\title{
Role of mesenchymal stem cell therapy in Crohn's disease
}

\author{
Jignesh Dalal' , Kimberly Gandy ${ }^{1}$ and Jos Domen ${ }^{1}$
}

Many trials of mesenchymal stem cells (MSCs) have been published in the past 5-6 y. MSCs inhibit T-cell alloreactivity in vitro by soluble factors and direct cell-to-cell contact. They are safe to infuse in humans with no acute toxicity and no ectopic tissue formation. Promising results of MSC infusion for graft-vs.-host disease and fistulizing Crohn's disease (CD) have been published. Treatment of $C D$ requires a comprehensive treatment approach to maintain symptomatic control, improve health-related quality-of-life measures, and minimize complications from the disease. In this review, we will discuss the results of clinical trials using a novel treatment in the form of MSCs for treatment of CD and related complications. Success of these phase I, II, and III trials have set the stage for usage of this novel treatment for children with CD.

C rohn's disease (CD) and ulcerative colitis (UC), the major forms of inflammatory bowel disease (IBD), represent a significant burden to health-care costs (1). The exact etiology remains unknown, but a variety of factors have been thought to be contributors, including environment, the individual immune response, and genetics. CD is chronic, uncontrolled inflammation of the intestinal mucosa, characterized by segmental transmural mucosal inflammation and granulomatous changes. Any part of the gastrointestinal tract from the oral cavity to the perianal region may be involved. Usually both conditions are chronic and relapsing. The usual practice is to increase therapy in a stepwise fashion, progressing through aminosalicylates (sulfasalazine, mesalazine), antibiotics (metronidazole, ciprofloxacin), corticosteroids, immunosuppressive medications including thioguanine compounds (mercaptopurine, azathioprine), methotrexate, and cyclosporin, and finally anti-tumor necrosis factor (TNF) drugs (2). Despite a systematic approach to therapy and the addition of new biologics, the need for intestinal resection in $\mathrm{CD}$ has remained stable (3). Primary and secondary failure to respond to approved therapies, inability to provide a surgical solution to fistulizing manifestations, and the recurrent need for surgeries remain challenges requiring novel therapies in this disorder (4).

Although the incidence and prevalence of $\mathrm{CD}$ are beginning to stabilize in high-incidence areas such as northern Europe and North America, they continue to rise in low-incidence areas such as southern Europe, Asia, and much of the developing world (5). Pediatric CD is more common than ulcerative colitis, with an annual incidence of $0.2-8.5$ per $100,000 \mathrm{popu}-$ lation (6). Most patients have a chronic intermittent disease course, $13 \%$ have an unremitting disease course, and 10\% have prolonged remission. Less than half require corticosteroids at any point and all require surgery at least once (7).

When cells from a bone marrow aspirate are cultured in plastic flasks, hematopoietic cells and hematopoietic stem cells (HSCs) do not adhere to the plastic and are removed with a change of medium. The remaining plastic-adherent cells were originally termed colony-forming unit fibroblasts because they formed fibroblast-like colonies ex vivo (8). They were later called mesenchymal stem cells (MSCs, an abbreviation for mesenchymal stromal cells as well) $(9,10)$. Like HSCs, MSCs are rare in the bone marrow, representing 1 in 10,000 nucleated cells. MSCs are multipotent bone marrow cells able to differentiate in vitro and in vivo into tissues of mesenchymal origin in mice. Moreover, these MSCs provide support for the growth and differentiation of hematopoietic progenitor cells in bone marrow microenvironments and, in animal models, promote engraftment of hemopoietic cells (11). The unexpected observation that MSCs inhibited T-cell proliferation in vitro in 2002 2003 by three independent investigators opened the door for use of MSCs for autoimmune disorders, first in animal models and then in humans $(10,12,13)$. In coculture experiments with allogeneic lymphocytes, MSCs do not induce lymphocyte proliferation, interferon- $\gamma$ production, or upregulation of activation markers. Despite this ex vivo property, survival of infused allogenic MSCs in immunocompetent mice was estimated to be less than $40 \mathrm{~d}$. When mice were rechallenged, survival of infused MSCs was less than $5 \mathrm{~d}$. There was also evidence of immune memory induction by MSCs, suggesting that MSCs cannot completely evade the immune response and are eventually rejected $(12,14)$.

MSCs suppress proliferation of activated lymphocytes in vitro in a dose-dependent, non-human leukocyte antigen-restricted manner (12). In a baboon skin-graft model, Bartholomew and co-workers showed that infusion of ex vivo expanded donorderived or third-party cells prolonged the time to rejection of histoincompatible skin grafts (12). Furthermore, infused cells improve the outcome of acute renal, neural, and lung injury, 
possibly by promoting a shift from production of proinflammatory cytokines to anti-inflammatory cytokines at the site of injury (15-17). In 2005, Zappia and co-workers demonstrated that the intravenous (i.v.) injection of syngeneic MSCs ameliorated the clinical course of myelin oligodendrocyte glycoprotein-induced experimental autoimmune encephalomyelitis and reduced demyelination and leukocyte infiltration of the central nervous system (16).Thus far, MSCs have proven to be safe and have not resulted in toxicity or ectopic tissue growth in an increasing number of human trials (18-20). However, as reported by Tolar et al., the potential exists for allogenic murine MSCs carrying a cytogenetic abnormality after multiple passages to produce sarcoma in the lung and extremities in recipient animals (21). This should be considered when designing trials (22).

\section{PATHOPHYSIOLOGY OF CD}

Twin and family studies suggest a strong genetic influence. For example, approximately $50 \%$ of monozygotic twins and $30 \%$ of offspring of two affected parents developed the disease (23). Linkage analysis and positional cloning strategies, together with subsequent genome-wide association studies, have identified more than 30 distinct genetic loci that confer susceptibility. Some of the most strongly associated genes included CARD15, the IBD5 locus, the autophagy genes ATG16L1 and IRGM, and the interleukin (IL)-23 receptor (24). In CD, it is estimated that the genes identified so far account for less than $20 \%$ of the total genetic risk (25). Polymorphisms in identified genes, and as-yet undiscovered genes, may confer susceptibility by contributing to mucosal barrier dysfunction, the innate immunodeficiency state, or by influencing the propagation of chronic inflammation in the tertiary phase of the disease (24).

Cytokines are a group of low-molecular-weight peptides that are active at very low concentrations and bind to specific receptors to produce autocrine, paracrine, and other endocrine effects. Proinflammatory cytokines-chemokines with altered adaptive and innate responses-are thought to play a key role in the pathogenesis of IBD (24). In CD, the major cytokines arise from T-helper cell (Th) 1 and Th17 CD4 T-cell differentiation and consist of interferon (IFN) and IL-17/IL-22 generated by these types of differentiation (26). Human trials with anticytokine therapy have been successful, especially with TNF antagonist, in treatment of CD refractory to corticosteroids (27). Approximately one-third of patients do not respond to anti-TNF therapy, and an additional one-third subsequently lose response or become intolerant $(28,29)$. Other anticytokine therapies with anti-p40 IL-12/23, anti-IFN- $\gamma$, anti-IL-6 receptor antibodies, and granulocyte-macrophage colonystimulating factor (GM-CSF) have met with variable success. In a placebo-controlled and open-label human trial of ustekinumab, a fully human immunoglobulin G1 (IgG1) monoclonal antibody against the $\mathrm{p} 40$ subunit of interleukin-12/23, involving 131 patients, the response in the ustekinumab group was superior to that in the placebo arm $(53 \%$ and $30 \%, P=0.02)$ at $4 \mathrm{wk}$. In a subgroup of 49 patients who were previously given infliximab, clinical response to ustekinumab was significantly greater than that in the group given placebo (59 vs. $15 \%$ at week $4, P<0.05)(30)$. A second trial of anti-IL-12 (ABT874/J695, Wyeth Research and Abbott Laboratories) used a recombinant, exclusively human-sequence, full-length IgG1 antibody, genetically modified to recognize IL-12 p40 protein. The response rate was significantly higher in the group given $3 \mathrm{mg} / \mathrm{kg}$ than in the placebo group at the end of the 8-wk treatment period ( $75 \%$ vs. $25 \%, P=0.03$ ) (31). Similarly, in another human trial of fontolizumab, a humanized anti-IFN involving 133 patients, although there was no statistically significant difference in clinical response between the fontolizumab and placebo groups after a single dose at day 28 , patients receiving two different doses of fontolizumab $28 \mathrm{~d}$ apart demonstrated a doubled response rate at day 56 compared with those receiving placebo: $32 \%(9 / 28)$ vs. $69 \%(22 / 32, P=0.02)$ vs. $67 \%$ $(21 / 31, P=0.03)$ for the placebo, 4 and $10 \mathrm{mg} / \mathrm{kg}$ fontolizumab groups, respectively (32). In a small trial conducted in Japan, anti-IL-6 receptor antibody was given intravenously in randomized placebo-controlled fashion. At the final evaluation, $80 \%$ of the patients ( 8 of 10 ) given biweekly antibody had a clinical response as compared with $31 \%$ of the placebo-treated patients ( 4 of $13 ; P=0.019$ ) (33). In an attempt to boost innate immune responses, GM-CSF was tested in a randomized placebo-controlled trial in $\mathrm{CD}$. A total of 123 patients underwent randomization at a 2:1 ratio to receive GM-CSF $(6 \mu \mathrm{g} / \mathrm{kg}$ of body weight) or placebo subcutaneously daily for $56 \mathrm{~d}$. Clinical response, defined as a decrease from baseline of at least 100 points in the Crohn's Disease Activity Index (CDAI) score and remission on day 57 , was significantly higher in the sargramostim group than in the placebo group ( $48 \%$ vs. $26 \%$, $P=0.01$, and $40 \%$ vs. $19 \%, P=0.01$, respectively) (34).

A considerable body of literature suggesting an association between the microbiota and the immune system has recently emerged $(35,36)$. Shifts in the intestinal microenvironment may lead to changes in the microbiota known as dysbiosis. Dysbiosis may increase susceptibility to intestinal inflammation (37). In support of this hypothesis, T-bet ${ }^{-/-} \mathrm{Rag}^{2^{-/-}}$(TRUC) mice spontaneously develop dysbiosis and colitis, which can eventually progress to colorectal cancer (38). Remarkably, microbiota transferred from these donors into wild-type mice can confer disease (39). Subsequent studies identified two proteobacteria that are overrepresented in TRUC mice: Proteus mirabilis and Klebsiella pneumoniae, as the colitogenic microbes (40). In contrast to the above-mentioned examples, coliform bacteria such as Lactobacillus caseican antagonize the proinflammatory effects induced by commensal Escherichia coli in human CD by downregulating proinflammatory mediators (41). Lactic acid bacteria, such as Lactobacillus plantarum and Lactobacillus brevis, repressed the mRNA expressions of IL-1- $\beta$, TNF- $\alpha$, and IFN- $\gamma$ and decreased the protein expressions of IL-1- $\beta$ and IL-6 proteins in the colon. They were successful in preventing activation of the transcription factor nuclear factor- $\mathrm{\kappa B}$, colon shortening, and myeloperoxidase productivity (42). In an important early study by Waidmann et al., Bacteroides vulgatus was able to prevent $E$. coli-induced colitis in gnotobiotic IL- $2^{-/-}$mice, suggesting that probiotic bacteria can prevent bacterium-induced IBD (43). 


\section{MECHANISM OF MSC ACTION}

The study of human MSCs derived from subcutaneous adipose tissue (hASCs) in the $5 \%$ dextran sulfate sodium (DSS) mouse model has shown that hASCs inhibit T-cell activation with the superantigen staphylococcal enterotoxin E (SEB), as measured by cytokine secretion and T-cell proliferation. The inhibitory effect was partially reversed when peripheral blood mononuclear cells (PBMCs) and hASCs were separated by a semipermeable Transwell membrane suggesting partial cell-cell contact dependence (44). Moreover, the coculture of allogeneic PBMCs and hASCs in the same chamber of the Transwell system fully restored their inhibitory activity on SEB-activated PBMCs situated in the other chamber, suggesting that PBMChASC contact induces the secretion of an immunosuppressive factor(s) for T cells. IL-10 production increased in a cellcell contact-dependent manner in cocultures of hASC with PBMCs or monocytes but not with T cells. IL-10 blockade partially reversed the inhibitory activity of hASC on T cells. Modifications in MSCs decrease or enhance their immunomodulatory effects (45-47). Duijvestein et al. recently showed that IFN- $\gamma$-stimulated MSCs (IMSCs), but not nonstimulated MSCs, showed a significantly attenuated DSS-induced colitis and trinitro-benzene sulfunate-induced colitis. Human MSCs significantly inhibited PBMC proliferation at lower PBMC:IMSC ratios compared with untreated MSCs, indicating that IMSCs have higher immunomodulatory capacities. Treatment with mouse IMSCs resulted in significantly lower serum amyloid A levels, confirming the decreased inflammatory responses observed in these animals. IMSC migration to the intestine was significantly increased during colitis induction, whereas MSC distribution was unaffected, suggesting that IMSCs gain homing potential to sites of inflammation (45). Ko et al. recently showed that when cells were coated with antiaddressin antibody and injected into C57BL6 mice with DSS-induced colitis, the mice showed dramatically improved survival rates, higher IBD therapeutic scores, and significantly improved body weight gain compared with mice injected with MSC-only, isotype Ab, free Ab plus MSCs, or vehicle-only controls (46). hASC-treated colitic mice had significantly higher numbers of $\mathrm{T}$ regulatory cells (Tregs) in mesenteric lymph nodes than untreated colitic mice, and they persisted for a long period of time. In vivo depletion of IL-10 or CD25+ $\mathrm{T}$ cells partially reversed the beneficial action of hASCs on colitis, demonstrating involvement of a therapeutic effect. When cells were coated with antibody against vascular cell adhesion molecule-1 (Ab VCAM-1-MSC), mice exhibited a percentage of Tregs nearly five times greater than with PBS-only-injected mice (analysis of variance, $P<0.0001$ ), whereas MSC-onlyinjected mice showed nearly a tripling of the Treg percentage compared with PBS-injected mice $(P<0.05$; ref. 46$)$.

Colons of hASC-treated mice contained reduced levels of inflammatory cytokines (TNF- $\alpha$, IFN- $\gamma$, IL- 6 , IL- $1 \beta$, and IL-12), chemokines (RANTES), and macrophage inflammatory protein-2 and increased levels of the anti-inflammatory/ regulatory cytokine IL-10 in comparison with untreated DSS colitic mice. This effect was not just a consequence of a diminished inflammatory infiltration in the mucosa because mononuclear cells isolated from the lamina propria of hASCtreated mice produced less TNF- $\alpha$, IL-12, and IFN- $\gamma$ on ex vivo culture, suggesting that hASC deactivated the colonic inflammatory response (44). Both syngeneic and allogeneic murine ASCs were as efficient as hASCs in ameliorating the colitis suggesting that the immunosuppressive action of ASCs is non-major histocompatibility complex (MHC)-restricted and that the infused ASCs are immune-tolerated by the host, which is convenient for future clinical application of these cells in $\mathrm{CD}(44)$.

\section{CELLULAR THERAPY CLINICAL TRIALS IN CD}

The results of human trials in CD are summarized in Table 1 (4,48-53). Cellular therapy can be divided into HSC therapy and MSC therapy. HSC therapy can be subdivided into autologous vs. allogenic; similarly, MSC therapy is subdivided into local vs. systemic in addition to allogenic vs. autologous.

\section{HSC THERAPY}

In 1995, an international committee developed guidelines on entry criteria and transplant protocols for severe autoimmune diseases and IBD. The committee recommended that autologous hematopoietic stem cell transplantation (HSCT) be preferred to allogeneic HSCT because of the lower risk of severe toxicity (54). Apart from case reports, two series have reported success of autologous HSCT for CD as the primary indication $(55,56)$. All the case reports or series have used high-dose cyclophosphamide with G-CSF for mobilization of HSCs and high-dose cyclophosphamide \pm ATG (equine or rabbit) as a preparative regimen with autologous stem cell infusion. The first phase I study from Chicago included 12 patients with active moderate to severe $\mathrm{CD}$ refractory to conventional therapies including anti-TNF treatment. Eleven of 12 patients entered a sustained remission after a median follow-up of 18.5 mo. Only 1 patient had developed recurrence of active CD (48). Another study published from Milan in 2008 included 4 patients. All had failed immunosuppressant treatment including anti-TNF therapy, and 2 had undergone multiple surgical resections. All had active CDAI of 258-404 at the time of transplantation. Three months after transplant, all patients had achieved clinical remission and complete endoscopic remission was achieved in 2 of 3 patients. Three of the 4 patients had sustained remission after a median follow-up of $16.5 \mathrm{mo}$. No mortality was observed in the two series (49). Currently, a phase III study originating from Nottingham, UK, is recruiting CD patients. The study is testing the role of early vs. late autologous HSCT in the treatment of refractory CD (http://clinicaltrials. gov/ct2/show/NCT00297193). Allogenic marrow transplantation has also proven to be useful for the treatment of IBD. In 11 patients who underwent allogenic marrow transplantation with myeloablative conditioning, at a median follow-up of 34 mo all 10 surviving patients were in complete remission of their hematologic malignancy and free of IBD symptoms, despite discontinuation of the usual immunosuppressive drugs after allogenic HSCT (50). A similar observation was made in a 
Table 1. Human trials of cellular therapy for refractory Crohn's disease

\begin{tabular}{|c|c|c|c|c|c|}
\hline $\begin{array}{l}\text { Types of cellular therapy with } \\
\text { indication }\end{array}$ & Source of cells & $\begin{array}{l}\text { Number of patients/ } \\
\text { route of administration }\end{array}$ & Response & Side effects & Reference \\
\hline $\begin{array}{l}\text { Autologous mobilized } \\
\text { hematopoietic stem cells for } \\
\text { refractory CD }\end{array}$ & Peripheral blood & 12/i.v. & $\begin{array}{l}11 / 12 \text { sustained clinical } \\
\text { remission }\end{array}$ & $\begin{array}{l}\text { Cytopenias, neutropenic } \\
\text { fever, and disease- } \\
\text { related fever, diarrhea, } \\
\text { anorexia, nausea, and } \\
\text { vomiting }\end{array}$ & (48) \\
\hline $\begin{array}{l}\text { Autologous mobilized } \\
\text { hematopoietic stem cells for } \\
\text { refractory CD }\end{array}$ & Peripheral blood & 4/i.v. & $\begin{array}{l}3 / 4 \text { patients } \\
\text { experienced both } \\
\text { clinical and endoscopic } \\
\text { remission. Complete } \\
\text { fistula closure in all }\end{array}$ & $\begin{array}{l}\text { Cytopenia, perianal } \\
\text { abscess, pleural and } \\
\text { pericardial effusions, BK } \\
\text { virus-induced hematuria }\end{array}$ & (49) \\
\hline $\begin{array}{l}\text { Allogeneic HSCT for } \\
\text { patients with hematological } \\
\text { malignancy and IBD }\end{array}$ & & 11/i.v. & $\begin{array}{l}10 ; \text { all } 10 \text { are alive and in } \\
\text { remission }\end{array}$ & $\begin{array}{l}\text { One death due to } \\
\text { opportunistic infection }\end{array}$ & (50) \\
\hline $\begin{array}{l}\text { Autologous MSCs for luminal } \\
\text { refractory CD }\end{array}$ & BM & 9/i.v. & $\begin{array}{l}\text { Reduction in CDAl of } 70 \\
\text { points in } 3 \text { patients }\end{array}$ & $\begin{array}{l}\text { Disease worsening in } \\
4 \text { patients, requiring } \\
\text { surgery or rescue therapy }\end{array}$ & (52) \\
\hline $\begin{array}{l}\text { Allogeneic MSCs for luminal } \\
\text { refractory CD }\end{array}$ & BM & $207^{+} /$i.v. & Trial in progress & & $\begin{array}{l}\text { Refer to } \\
\text { discussion } \\
\text { in text of the } \\
\text { ongoing trial by } \\
\text { Osiris }\end{array}$ \\
\hline $\begin{array}{l}\text { Autologous MSCs for } \\
\text { perianal fistula }\end{array}$ & Lipoaspirate & 24/local injection & $\begin{array}{l}17 \text { of } 24(71 \%) \text { fistula } \\
\text { healing }\end{array}$ & No significant side effects & (53) \\
\hline
\end{tabular}

BM, bone marrow; CD, Crohn's disease; CDAl, Crohn's Disease Activity Index; HSCT, hematopoietic stem cell therapy; IBD, inflammatory bowel disease; i.v., intravenous; MSC, mesenchymal stem cell.

study by McDonald et al., from Seattle, in which 4 of 5 patients followed for 4.5 to $15.3 \mathrm{y}$ after allogeneic HSCT for hematological malignancies with myeloablative conditioning regimen, remained free of $C D$ without immunosuppressive therapy. Normalization of serum alkaline phosphatase levels was noted in 2 of 3 patients with a clinical diagnosis of sclerosing cholangitis (51). Since the report in 1993 of the first CD patient who underwent autologous HSCT for lymphoma resulting in improvement of $\mathrm{CD}$, at least 25 patients have been reported who underwent HSCT for cancer, with remission achieved in 22 cases, over a median follow-up of 20 mo. Two patients died from infectious complications (3). Unlike allogenic HSCT, recurrence of $\mathrm{CD}$ in transplanted bowel points toward a significant role of the immune system rather than the mucosal barrier in the pathogenesis of $\mathrm{CD}$ (57).

\section{MSC THERAPY}

\section{Systemic Infusion of Human MSCs}

In the first human trial of systemic MSCs in CD, Onken et al., from Duke University, treated 10 patients who had failed previous treatment with steroids and immunosuppressants and had active disease; patients were randomized to receive either low- ( 2 million cells $/ \mathrm{kg}$ ) or high-dose (8 million cells/ $\mathrm{kg}$ ) i.v., allogenic, third-party, healthy, human bone marrowderived MSCs as i.v. infusions-in two doses $7 \mathrm{~d}$ apart. All nine evaluable patients had a decrease in CDAI score by day 28. Mean CDAI scores decreased significantly from baseline to day 28 (341 vs. 236, $P=0.004$, Wilcoxon signed rank). The primary end point was clinical response defined as a $\geq 100$-point reduction in CDAI. This response was achieved in 3 patients (33\%) by day 14,2 of whom met the end point within $7 \mathrm{~d}$ of the first infusion. All clinical responders had previously failed infliximab therapy. Mean IBD quotient scores increased significantly from baseline to day 28 ( 113 vs. $146, P=0.008$, Wilcoxon signed rank). IBD quotient scores increased to $\geq 170$ in $22 \%$ of patients by day 14 and $38 \%$ by day 28 . There appeared to be an association between mean change in IBD quotient and clinical response at day $28(P=0.07$, Wilcoxon rank sum). Although not statistically significant, the mean reduction in the CDAI score at day 28 was greater in the high-dose than in the 
low-dose group ( -137 vs. $-65, P=0.39$, Wilcoxon rank sum). All infusions were well tolerated, and there were no treatmentrelated serious adverse events58).

Another phase I study of autologous bone marrowderived MSCs for luminal refractory $\mathrm{CD}$ was published in the Netherlands. Enough MSCs were expanded in 9 of 10 patients to administer two doses of $1-2 \times 10^{6}$ cells $/ \mathrm{kg}$ body weight, intravenously, $7 \mathrm{~d}$ apart. All patients had previously failed corticosteroids, at least two anti-TNF drugs, and 9 of 10 patients also had failed two immunosuppressants (thiopurine and methotrexate). In this study, no clear signal of efficacy was observed; remission was not achieved in any patient, and 3 patients had a reduction of at least 70 points in CDAI, but the disease worsened significantly in 4 patients requiring surgery (three cases) or rescue medication (one case) within $14 \mathrm{wk}$ after cell treatment. Endoscopy improved in two cases, but no significant changes in C-reactive protein levels were seen (52). The currently ongoing largest, randomized, placebo-controlled, double-blind phase III study of prochymal (allogenic marrow-derived MSCs) in CD was initiated in 2007 by Osiris (http://clinicaltrials.gov/ct2/show/NCT00294112). The study plan is to enroll 270 patients with active CD (CDAI 250-450) who have a history of treatment failure with or intolerance to steroids, immunosuppressants, and biologics. Patients are randomized to receive four infusions over $2 \mathrm{wk}$ of either 600 million cells (low dose: two infusions of $200 \times 10^{6} \mathrm{hMSCs}$ in week 1 , then two infusions of $100 \times 10^{6} \mathrm{hMSCs}$ in week 2), 1,200 million cells (high dose: two infusions of $400 \times 10^{6}$ hMSCs in week 1 , then two infusions of $200 \times 10^{6}$ hMSCs in week 2) or placebo. The primary end point of the study is remission at day 28 with secondary end points being clinical response, improved quality of life (increased IBD quotient score), and decreased number of draining fistulae.

\section{LOCAL INJECTION OF MSCS IN CD}

The first trial of cell therapy using autologous MSCs (ASCs) obtained from a lipoaspirate for local treatment of fistulae for CD in 5 patients was published in 2005 (19). The same group published a phase II, multicenter, randomized controlled trial describing the effectiveness and safety of ASCs in the treatment of complex perianal fistulas in 2009. Patients with complex perianal fistulas (cryptoglandular origin, $n=35$; associated with $\mathrm{CD}, n=14$ ) were randomly assigned to intralesional treatment with fibrin glue or fibrin glue plus 20 million ASCs. Fistula healing and quality of life (SF-12 questionnaire) were evaluated at $8 \mathrm{wk}$ and $1 \mathrm{y}$. If healing was not seen at $8 \mathrm{wk}$, a second dose of fibrin glue or fibrin glue plus 40 million ASCs was administered. Fistula healing was observed in 17 (71\%) of 24 patients who received ASCs in addition to fibrin glue, compared with 4 (16\%) of 25 patients who received fibrin glue alone (relative risk for healing, 4.43; confidence interval, 1.74-11.27; $P<0.001)$. The proportion of patients with healing was similar in $\mathrm{CD}$ and non-CD subgroups. ASCs were also more effective than fibrin glue alone in patients with a suprasphincteric fistulous tract $(P=0.001)$. Quality-of-life scores were higher in patients who received ASCs than in those who received fibrin glue alone. At 1-y follow-up, the recurrence rate in patients treated with ASCs was 17.6\%. Both treatments were well tolerated (53). In a second study, published recently, a local injection of autologous marrow-derived MSCs was given to nine patients with perianal and one patient with enterocutaneous fistulas. Injections of a median of $20 \times 10^{6}$ cells (range 15-30) were given every $4 \mathrm{wk}$ until a response was obtained or no more cells were available. Complete fistula closure sustained for $1 \mathrm{y}$ was obtained in 7 patients and a response (reduction of at least $50 \%$ of fistula tracts) in 3. Furthermore, all 9 patients with perianal fistulas had active disease in the rectum at baseline, and healing of rectal lesions was observed in the 7 patients who underwent endoscopy at month 12 of follow-up. Thus, the latter study suggests a considerable therapeutic benefit of local injection of MSCs in fistulizing lesions (4). At this stage, reasons for the apparent discrepancies between efficacy of local injection of MSCs for treatment of fistulas compared with systemic administration for treatment of luminal CD are not completely clear. MSCs have been reported to home to sites of injury and disease following i.v. infusion and contribute to the repair process. The expression of adhesion molecules and chemokine receptors on MSCs may be responsible for their ability to migrate selectively to sites of inflammation through a ICAM1- and VCAM1-dependent interaction with endothelial cells (59). In an experimental model of colitis, systemically injected human adipose tissue-derived MSCs were detected in the mesenteric lymph nodes and spleen of the recipient colitic mice 1-3 d post injection (44). Interestingly, labeled MSCs were recruited by the inflamed colon but not by the noninflamed intestine. However, the proportion of cells recruited to inflamed or damaged organs and the survival of cells at sites of inflammatory lesions remain to be clarified, a necessary prerequisite for optimizing a potential systemic treatment. In studies showing efficacy of local injections, of human autologous MSCs, $30-60 \times 10^{6}$ are injected in a single fistulous tract, and these injections are generally repeated $(4,53)$. In a study using systemic injection for treatment of luminal disease, a higher number of 100-400 $\times 10^{6}$ allogenic or autologous MSCs were injected (52). Considering the extension of the inflamed intestine, and the fact that only a portion of the MSCs will reach the inflamed organ, the cell density at sites of luminal inflammation would be considerably lower than that achieved in fistula tracts by local injection. To circumvent this, Ghosh et al., from the United Kingdom, injected haploidentical MSCs after catheterization of the mesenteric artery via the femoral route into a 35-y-old patient with severe refractory fistulizing $\mathrm{CD}$ failing all conventional therapies, biological therapies, and surgical defunctioning ileostomy. The patient received $10^{5} / \mathrm{kg}$ MSCs, and $4 \mathrm{wk}$ later a second dose of $10^{6} / \mathrm{kg}(60)$. The pretreatment CDAI was 384; it dropped to 2582 weeks after the first infusion and remained as such at the time of the second infusion administered after $4 \mathrm{wk}$. Magnetic resonance imaging of the abdomen/pelvis post-MSC treatment showed slight changes in the transphincteric fistulae on the right and an unchanged horseshoe intersphincteric extension on the left side. There was no adverse effect. All the above studies point 
to a difference in cell density achieved at inflammatory sites, with systemic and local injections. Ongoing trials are testing fourfold higher systemic doses (61).

\section{TIMING OF MSC TREATMENT}

A recent study published by Duijvestein et al. showed that azathioprine, methotrexate, and anti-TNF compounds do not change the phenotype, morphology, viability, differentiation, and functional capabilities when incubated with MSCs in physiological concentrations. Conversely, the presence of MSCs did not hamper the immunosuppressive effect of those commonly used medications for treatment of $\mathrm{CD}$ (62). In another recent study examining the mechanism of various anti-TNF medications, Vos et al. found that anti-TNF antibodies differentiate blood-derived macrophage into regulatory phenotype $\left(\mathrm{M} \varphi_{\text {ind }}\right)$ in an FC fragment-dependent fashion. The $\mathrm{M} \varphi_{\text {ind }}$ phenotype has anti-inflammatory properties because it inhibits the proliferation of activated T cells, produces IL-10, and expresses regulatory macrophage marker CD206 (63). Similarly, MSCs can turn macrophages into the regulatory phenotype, raising the possibility of synergism (64). All of the above make MSC treatment very attractive for use with standard CD therapy to enhance induction and then, in maintenance, to enable more rapid tapering of immunosuppressive therapy.

\section{CONCLUSION}

Many human trials of autologous and allogenic MSCs completed in the past 5-6 y have demonstrated both short-term safety and efficacy of that modality of cellular therapy for CD and acute graft-vs.-host disease. There is an apparent discrepancy in response to MSC therapy for CD based on route of administration (i.v. vs. intralesional vs. intra-arterial). The reason for this is speculative, but it might reflect the density of the injected cells at the lesion site. Ongoing trials with higher doses may help in answering this question. Trials of allogenic MSCs derived from bone marrow in children with CD should be initiated soon to test that modality for use in children because they may respond better than adults. Many challenges remain ahead, including determining the best source of MSCs, the best administration route, and the density of cells needed at the lesion site to guarantee effective therapy. It will be particularly important to determine which combinations, including biologics, are more effective in the treatment of $\mathrm{CD}$.

\section{REFERENCES}

1. Kappelman MD, Rifas-Shiman SL, Porter CQ, et al. Direct health care costs of Crohn's disease and ulcerative colitis in US children and adults. Gastroenterology 2008;135:1907-13.

2. Strober W, Fuss I, Mannon P. The fundamental basis of inflammatory bowel disease. J Clin Invest 2007;117:514-21.

3. García-Bosch O, Ricart E, Panés J. Review article: stem cell therapies for inflammatory bowel disease-efficacy and safety. Aliment Pharmacol Ther 2010;32:939-52.

4. Ciccocioppo R, Bernardo ME, Sgarella A, et al. Autologous bone marrowderived mesenchymal stromal cells in the treatment of fistulising Crohn's disease. Gut 2011;60:788-98.

5. Loftus EV Jr. Clinical epidemiology of inflammatory bowel disease: Incidence, prevalence, and environmental influences. Gastroenterology 2004;126:1504-17.
6. Parashette KR, Makam RC, Cuffari C. Infliximab therapy in pediatric Crohn's disease: a review. Clin Exp Gastroenterol 2010;3:57-63.

7. Andres PG, Friedman LS. Epidemiology and the natural course of inflammatory bowel disease. Gastroenterol Clin North Am 1999;28:255-81, vii.

8. Prockop DJ. Marrow stromal cells as stem cells for nonhematopoietic tissues. Science 1997;276:71-4.

9. Lazarus HM, Haynesworth SE, Gerson SL, Rosenthal NS, Caplan AI. Ex vivo expansion and subsequent infusion of human bone marrow-derived stromal progenitor cells (mesenchymal progenitor cells): implications for therapeutic use. Bone Marrow Transplant 1995;16:557-64.

10. Le Blanc K, Tammik L, Sundberg B, Haynesworth SE, Ringdén O. Mesenchymal stem cells inhibit and stimulate mixed lymphocyte cultures and mitogenic responses independently of the major histocompatibility complex. Scand J Immunol 2003;57:11-20.

11. Noort WA, Kruisselbrink AB, in’t Anker PS, et al. Mesenchymal stem cells promote engraftment of human umbilical cord blood-derived CD34(+) cells in NOD/SCID mice. Exp Hematol 2002;30:870-8.

12. Bartholomew A, Sturgeon C, Siatskas M, et al. Mesenchymal stem cells suppress lymphocyte proliferation in vitro and prolong skin graft survival in vivo. Exp Hematol 2002;30:42-8.

13. Di Nicola M, Carlo-Stella C, Magni M, et al. Human bone marrow stromal cells suppress T-lymphocyte proliferation induced by cellular or nonspecific mitogenic stimuli. Blood 2002;99:3838-43.

14. Zangi L, Margalit R, Reich-Zeliger S, et al. Direct imaging of immune rejection and memory induction by allogeneic mesenchymal stromal cells. Stem Cells 2009;27:2865-74.

15. Ortiz LA, Gambelli F, McBride C, et al. Mesenchymal stem cell engraftment in lung is enhanced in response to bleomycin exposure and ameliorates its fibrotic effects. Proc Natl Acad Sci USA 2003;100:8407-11.

16. Zappia E, Casazza S, Pedemonte E, et al. Mesenchymal stem cells ameliorate experimental autoimmune encephalomyelitis inducing T-cell anergy. Blood 2005;106:1755-61.

17. Tögel F, Hu Z, Weiss K, Isaac J, Lange C, Westenfelder C. Administered mesenchymal stem cells protect against ischemic acute renal failure through differentiation-independent mechanisms. Am J Physiol Renal Physiol 2005;289:F31-42.

18. Le Blanc K, Rasmusson I, Sundberg B, et al. Treatment of severe acute graft-versus-host disease with third party haploidentical mesenchymal stem cells. Lancet 2004;363:1439-41.

19. García-Olmo D, García-Arranz M, Herreros D, Pascual I, Peiro C, Rodríguez-Montes JA. A phase I clinical trial of the treatment of Crohn's fistula by adipose mesenchymal stem cell transplantation. Dis Colon Rectum 2005;48:1416-23.

20. Le Blanc K, Frassoni F, Ball L, et al.; Developmental Committee of the European Group for Blood and Marrow Transplantation. Mesenchymal stem cells for treatment of steroid-resistant, severe, acute graft-versushost disease: a phase II study. Lancet 2008;371:1579-86.

21. Tolar J, Nauta AJ, Osborn MJ, et al. Sarcoma derived from cultured mesenchymal stem cells. Stem Cells 2007;25:371-9.

22. Alexander B, Mohseny PCWH. Mesenchymal Tumors: When Stem Cells Go Mad. Stem Cells 2011;29.

23. Halme L, Paavola-Sakki P, Turunen U, Lappalainen M, Farkkila M, Kontula K. Family and twin studies in inflammatory bowel disease. World J Gastroenterol 2006;12:3668-72.

24. Sewell GW, Marks DJ, Segal AW. The immunopathogenesis of Crohn's disease: a three-stage model. Curr Opin Immunol 2009;21:506-13.

25. Barrett JC, Hansoul S, Nicolae DL, et al.; NIDDK IBD Genetics Consortium; Belgian-French IBD Consortium; Wellcome Trust Case Control Consortium. Genome-wide association defines more than 30 distinct susceptibility loci for Crohn's disease. Nat Genet 2008;40:955-62.

26. Strober W, Fuss IJ. Proinflammatory cytokines in the pathogenesis of inflammatory bowel diseases. Gastroenterology 2011;140:1756-67.

27. Behm BW, Bickston SJ. Tumor necrosis factor-alpha antibody for maintenance of remission in Crohn's disease. Cochrane Database Syst Rev 2008:CD006893.

28. Akobeng AK, Zachos M. Tumor necrosis factor-alpha antibody for induction of remission in Crohn's disease. Cochrane Database Syst Rev 2004:CD003574. 
29. Cottone M, Criscuoli V. Infliximab to treat Crohn's disease: an update. Clin Exp Gastroenterol 2011;4:227-38.

30. Sandborn WJ, Feagan BG, Fedorak RN, et al.; Ustekinumab Crohn's Disease Study Group. A randomized trial of Ustekinumab, a human interleukin-12/23 monoclonal antibody, in patients with moderate-tosevere Crohn's disease. Gastroenterology 2008;135:1130-41.

31. Mannon PJ, Fuss IJ, Mayer L, et al.; Anti-IL-12 Crohn's Disease Study Group. Anti-interleukin-12 antibody for active Crohn's disease. N Engl J Med 2004;351:2069-79.

32. Hommes DW, Mikhajlova TL, Stoinov S, et al. Fontolizumab, a humanised anti-interferon gamma antibody, demonstrates safety and clinical activity in patients with moderate to severe Crohn's disease. Gut 2006;55:1131-7.

33. Ito H, Takazoe M, Fukuda Y, et al. A pilot randomized trial of a human anti-interleukin-6 receptor monoclonal antibody in active Crohn's disease. Gastroenterology 2004;126:989-96; discussion 947.

34. Korzenik JR, Dieckgraefe BK, Valentine JF, Hausman DF, Gilbert MJ; Sargramostim in Crohn's Disease Study Group. Sargramostim for active Crohn's disease. N Engl J Med 2005;352:2193-201.

35. Neish AS. Microbes in gastrointestinal health and disease. Gastroenterology 2009;136:65-80.

36. Porter CK, Tribble DR, Aliaga PA, Halvorson HA, Riddle MS. Infectious gastroenteritis and risk of developing inflammatory bowel disease. Gastroenterology 2008; $135: 781-6$.

37. Chow J, Tang H, Mazmanian SK. Pathobionts of the gastrointestinal microbiota and inflammatory disease. Curr Opin Immunol 2011;23:473-80.

38. Garrett WS, Punit S, Gallini CA, et al. Colitis-associated colorectal cancer driven by T-bet deficiency in dendritic cells. Cancer Cell 2009;16:208-19.

39. Garrett WS, Lord GM, Punit S, et al. Communicable ulcerative colitis induced by T-bet deficiency in the innate immune system. Cell 2007;131:33-45.

40. Garrett WS, Gallini CA, Yatsunenko T, et al. Enterobacteriaceae act in concert with the gut microbiota to induce spontaneous and maternally transmitted colitis. Cell Host Microbe 2010;8:292-300.

41. Llopis M, Antolin M, Carol M, et al. Lactobacillus casei downregulates commensals' inflammatory signals in Crohn's disease mucosa. Inflamm Bowel Dis 2009;15:275-83.

42. Lee HS, Han SY, Bae EA, et al. Lactic acid bacteria inhibit proinflammatory cytokine expression and bacterial glycosaminoglycan degradation activity in dextran sulfate sodium-induced colitic mice. Int Immunopharmacol 2008;8:574-80.

43. Waidmann M, Bechtold O, Frick JS, et al. Bacteroides vulgatus protects against Escherichia coli-induced colitis in gnotobiotic interleukin-2deficient mice. Gastroenterology 2003;125:162-77.

44. Gonzalez-Rey E, Anderson P, González MA, Rico L, Büscher D, Delgado M. Human adult stem cells derived from adipose tissue protect against experimental colitis and sepsis. Gut 2009;58:929-39.

45. Duijvestein M, Wildenberg ME, Welling MM, et al. Pretreatment with interferon-? enhances the therapeutic activity of mesenchymal stromal cells in animal models of colitis. Stem Cells 2011;29:1549-58.

46. Ko IK, Kim BG, Awadallah A, et al. Targeting improves MSC treatment of inflammatory bowel disease. Mol Ther 2010;18:1365-72.

47. Liotta F, Angeli R, Cosmi L, et al. Toll-like receptors 3 and 4 are expressed by human bone marrow-derived mesenchymal stem cells and can inhibit their T-cell modulatory activity by impairing Notch signaling. Stem Cells 2008;26:279-89.
48. Oyama Y, Craig RM, Traynor AE, et al. Autologous hematopoietic stem cell transplantation in patients with refractory Crohn's disease. Gastroenterology 2005;128:552-63.

49. Cassinotti A, Annaloro C, Ardizzone S, et al. Autologous haematopoietic stem cell transplantation without CD34+ cell selection in refractory Crohn's disease. Gut 2008;57:211-7.

50. Ditschkowski M, Einsele H, Schwerdtfeger R, et al. Improvement of inflammatory bowel disease after allogeneic stem-cell transplantation. Transplantation 2003;75:1745-7.

51. Lopez-Cubero SO, Sullivan KM, McDonald GB. Course of Crohn's disease after allogeneic marrow transplantation. Gastroenterology 1998; 114:433-40.

52. Duijvestein M, Vos AC, Roelofs H, et al. Autologous bone marrow-derived mesenchymal stromal cell treatment for refractory luminal Crohn's disease: results of a phase I study. Gut 2010;59:1662-9.

53. Garcia-Olmo D, Herreros D, Pascual I, et al. Expanded adipose-derived stem cells for the treatment of complex perianal fistula: a phase II clinical trial. Dis Colon Rectum 2009;52:79-86.

54. Gratwohl A, Passweg J, Bocelli-Tyndall C, et al.; Autoimmune Diseases Working Party of the European Group for Blood and Marrow Transplantation (EBMT). Autologous hematopoietic stem cell transplantation for autoimmune diseases. Bone Marrow Transplant 2005;35:869-79.

55. Martí JL, Mayordomo JI, Isla MD, Saenz A, Escudero P, Tres A. PBSC autotransplant for inflammatory bowel disease (IBD): a case of ulcerative colitis. Bone Marrow Transplant 2001;28:109-10.

56. Kreisel W, Potthoff K, Bertz H, et al. Complete remission of Crohn's disease after high-dose cyclophosphamide and autologous stem cell transplantation. Bone Marrow Transplant 2003;32:337-40.

57. Kaila B, Grant D, Pettigrew N, Greenberg H, Bernstein CN. Crohn's disease recurrence in a small bowel transplant. Am J Gastroenterol 2004;99:158-62.

58. Onken JE, et al. Successful outpatient treatment of refractory Crohn's disease using adult mesenchymal stem cells. American College of Gastroenterology Conference 2006, Las Vegas, NV, Abstract 121.

59. Chamberlain G, Fox J, Ashton B, Middleton J. Concise review: mesenchymal stem cells: their phenotype, differentiation capacity, immunological features, and potential for homing. Stem Cells 2007;25: 2739-49.

60. Dinesen L, Gallup D, Hanson J, et al. Mesenchymal stem cells administered via novel selective mesenteric artery cannulation for the treatment of severe refractory Crohn's disease. 4th Congress of ECCO 2009, Hamburg, Germany, Abstract 103.

61. Panés J, Benitez-Ribas D, Salas A. Mesenchymal stem cell therapy of Crohn's disease: are the far-away hills getting closer? Gut 2011; 60:742-4.

62. Duijvestein M, Molendijk I, Roelofs H, et al. Mesenchymal stromal cell function is not affected by drugs used in the treatment of inflammatory bowel disease. Cytotherapy 2011;13:1066-73.

63. Vos AC, Wildenberg ME, Arijs I et al. Regulatory macrophages induced by infliximab are involved in healing in vivo and in vitro. Inflamm Bowel Dis 2011; e-pub ahead of print 20 September 2011.

64. Maggini J, Mirkin G, Bognanni I, et al. Mouse bone marrow-derived mesenchymal stromal cells turn activated macrophages into a regulatory-like profile. PLoS ONE 2010;5:e9252. 